\title{
The pulmonary surfactant system matures upon pipping in the freshwater turtle Chelydra serpentina
}

\author{
Sonya D. Johnston ${ }^{1,2}$, Christopher B. Daniels ${ }^{1,2}$, David Cenzato ${ }^{2}$, Jeffrey A. Whitsett ${ }^{3}$ \\ and Sandra Orgeig $1,2, *$ \\ ${ }^{1}$ Department of Physiology and ${ }^{2}$ Department of Environmental Biology,University of Adelaide, Adelaide SA 5005, \\ Australia, ${ }^{3}$ Division of Pulmonary Biology and Neonatology, Children's Hospital Medical Center, Cincinnati \\ OH 45229-3039, USA \\ *Author for correspondence at address 2 (e-mail: sandra.orgeig@ adelaide.edu.au)
}

Accepted 19 November 2001

\begin{abstract}
Summary
Pulmonary surfactant (PS), a mixture of phospholipids (PL), neutral lipids and surfactant proteins (SP), lowers surface tension within the lung, which increases lung compliance and improves the removal of fluid at birth. Here, we have examined the expression of thyroid transcription factor-1 (TTF-1) and the surfactant protein SP-B, and also the composition of pulmonary surfactant lipids in the developing lung of the turtle Chelydra serpentina. Lavage and lung tissue were collected from late embryonic, pipped and hatchling turtles. TTF-1, a regulator of gene expression of surfactant proteins and cell differentiation in mammals, was detected using immunohistochemistry in epithelia of the gas-exchange area and conducting airways during late development. Expression declined in hatchlings. SP-B was detected in subsets of cells within the respiratory epithelium at all

stages sampled. The same cell types also stained for TTF1. Turtle surfactant lipids matured toward the end of incubation. Maximal secretion of both total phospholipids and disaturated phospholipid (DSP) occurred at the time of pipping, coincident with the onset of breathing. The DSP/PL ratio increased after pipping, whereas cholesterol levels (Chol) increased prior to pipping. This resulted in a decrease in the Chol/PL and Chol/DSP ratios after pipping. Thus, TTF-1 and SP-B appear to be highly conserved within the vertebrates. Maturation of surfactant phospholipid content occurred with the commencement of pulmonary ventilation.

Key words: thyroid transcription factor-1, surfactant protein, SP-B, phospholipid, cholesterol, lung, development, freshwater turtle, Chelydra serpentina.
\end{abstract}

\section{Introduction}

All lungs are lined with a layer of water that prevents desiccation of the fine respiratory epithelium. Consequently, the high surface tension generated decreases alveolar stability and lung compliance and increases the work of breathing (Possmayer, 1997). The presence of pulmonary surfactant, a complex mixture of phospholipids, neutral lipids and surfactant proteins, reduces surface tension within the lung, maintaining lung compliance and lung volume. Pulmonary surfactant is synthesized via the endoplasmic reticulum and Golgi apparatus of the alveolar type II cell. Here, lipids and proteins are packaged into lamellar inclusion bodies that are secreted into the aqueous hypophase, where they reorganize to produce tubular myelin (Weaver, 1998). Phospholipids are released from the tubular myelin and adsorb to the air-liquid interface, with the aid of the proteins, forming a monolayer, comprising disaturated phospholipids, unsaturated phospholipids and neutral lipids. Disaturated phospholipids, including disaturated phosphatidylcholine, are primarily responsible for lowering surface tension at low lung volumes (Possmayer, 1997). Unsaturated phospholipids and neutral lipids, such as cholesterol, are thought to aid respreading of the surface film upon inflation and to regulate the fluidity of phospholipids and their adsorption with fluctuating body temperatures (Daniels et al., 1995b, 1998). Of the four surfactant proteins, SP-A and SP-D are thought to be active in innate lung defense (Weaver and Whitsett, 1991), while SP-B and SP-C have been implicated in the formation and maintenance of the surface film (Weaver, 1998).

Transcription of genes encoding SP-A, SP-B and SP-C is regulated by several transcription proteins, including thyroid transcription factor 1 (TTF-1), which binds to the DNA within the promoter region of the target gene (Bohinski et al., 1994; Bruno et al., 1995; Kelly et al., 1996). TTF-1 activates SP-B gene expression by binding to several cis-acting elements in the $5^{\prime}$-flanking region of the gene (Bohinski et al., 1994). TTF-1 is important for lung morphogenesis (Lazzaro et al., 1991; Minoo et al., 1995) and respiratory epithelial cell differentiation (Bohinski et al., 1994) during lung development and injury. Immunohistochemical studies have shown that TTF-1 is expressed in the nuclei of respiratory epithelial cells 
in the early stages of lung formation in both mammals (Stahlman et al., 1996; Zhou et al., 1996) and birds (Zeng et al., 1998), and is subsequently restricted to peripheral respiratory units throughout development (Zeng et al., 1998; Zhou et al., 1996), whereas staining for the SP-B peptide occurs later in development and is confined to the cytoplasm of type II cells in mammals (Khoor et al., 1994; Zhou et al., 1996) and epithelia of the parabronchi in birds (Zeng et al., 1998). To date, the factors regulating lung development in many reptiles have not been described.

In contrast, the development of the pulmonary surfactant system has been well documented in eutherians. It is one of the last systems to mature, characterized by an increase in extracellular and intracellular phospholipids, enrichment of disaturated phospholipids and the secretion of surfactant proteins in lung and amniotic fluid (Benson et al., 1983; Torday and Nielson, 1981). Both endogenous and exogenous corticosteroids induce synthesis of pulmonary surfactant in the mammalian fetal lung by stimulating enzymes involved in phospholipid synthesis, accelerating lamellar body development and influencing intracellular and extracellular concentrations of surfactant proteins (Merrill and Ballard, 1998). Unlike viviparous species, oviparous species, such as the snapping turtle Chelydra serpentina, lack the constant maternal-fetal exchange of nutrients and steroid hormones throughout development. Recent evidence suggests that maternal steroid hormones are present in freshly laid bird (Schwabl, 1993) and reptile eggs (Janzen et al., 1998). In addition, maternal triiodothyronine and thyroxine are found in avian albumin and yolk (Prati et al., 1992; Wilson and McNabb, 1997), whereas maternal antibodies are transferred via the egg to the developing chicken embryo (Katz et al., 1986). Deposition of such hormones and antibodies occurs prior to laying and, therefore, the action of such hormones is under embryonic control. Such differences in the availability of hormones may further impact on the development of the pulmonary surfactant system. Moreover, hatching is a much lengthier process than birth. The embryo must break through the extra-embryonic membranes and calcareous shell to draw its first breath, termed pipping, where it remains for some time, aerating its lungs. Therefore, the development and regulation of the surfactant system in the snapping turtle may differ substantially from those of mammals.

In addition, reptilian lung morphology varies drastically from that of the bronchoalveolar lung of mammals. Turtles possess a multicameral lung, comprising a cartilaginous primary intrapulmonary bronchus that communicates with several distinct chambers, from which the respiratory units, termed ediculae, are derived (Fleetwood and Munnell, 1996; Pastor et al., 1989; Perry et al., 1989). The respiratory units of reptile lungs are 1000-fold greater, with 70-fold greater respiratory surface area than the alveoli of similar sized mammals (Daniels et al., 1995a). Previously, lamellar bodies and an osmophilic surface film have been observed in the adult turtle lung (Meban, 1977; Pastor et al., 1989; Solomon and Purton, 1984). Since SP-B is instrumental in the generation of lamellar bodies in mammals
(Clark et al., 1995) and SP-A (Sullivan et al., 1998; Zeng et al., 1998), SP-B (Miller et al., 2001; Zeng et al., 1998) and SP-D (Miller et al., 2001) are highly conserved within the vertebrates, it is predicted that SP-B will also be present in the snapping turtle lung. Reptilian pulmonary surfactant prevents adherence of apposing respiratory epithelia (Daniels et al., 1996), regulates fluid balance (Orgeig et al., 1997), may offer resistance to evaporative water loss with decreasing temperature (Meban, 1981) and may have important roles in innate lung defense in the testudian lung (Sullivan et al., 1998). There has been extensive research on the function of surfactant in freshwater and marine turtles (Daniels et al., 1995a, 1996; Lau and Keough, 1981; Meban, 1980, 1981; Orgeig et al., 1997), and recently our laboratory published two studies on the development of the surfactant system in the green sea turtle, Chelydra serpentina (Johnston et al., 2001; Sullivan et al., 2001). The present study describes the development of the surfactant lipids and the temporal-spatial location of TTF-1 and SP-B throughout the latter part of incubation in the developing multicameral lung of a freshwater turtle, the snapping turtle.

\section{Materials and methods \\ Collection and incubation of eggs}

Six clutches of snapping turtle Chelydra serpentina L. eggs were collected from nests in the Valentine National Wildlife Refuge, Cherry County, NE, USA in mid-June, 1998. Snapping turtle eggs were collected under authority granted by collecting permit number 98-77 from the Nebraska Game and Parks Commission and by Special Use Permit number 85552 issued by the US Fish and Wildlife Service. Nests less than $12 \mathrm{~h}$ old were carefully excavated and eggs were placed in coolers containing damp moss and transported to Colorado State University for incubation. Individual clutches were divided into two groups and transferred to plastic boxes containing fine vermiculite (approximately $5 \mathrm{~mm}$ in diameter) with a gravimetric water content of $1 \mathrm{~g} \mathrm{~g}^{-1}$ dry mass, resulting in a water potential of $-200 \mathrm{kPa}$ or wetter (Packard et al., 1987). Containers were weighed after the eggs were deposited, then sealed and placed in two constant temperature cabinets at $26^{\circ} \mathrm{C}$, producing a male cohort (Yntema, 1981). Boxes were rotated throughout the cabinets daily to minimize exposure to fluctuations in temperature within the cabinets. Containers were weighed weekly and distilled water was added to the vermiculite until the initial mass of the container was reached.

\section{Antibodies and immunohistochemistry}

\section{Antibodies}

The rabbit polyclonal antibody, generated against a synthetic peptide spanning amino acid residues 110-122 of rat TTF-1, was provided by Dr Roberto Di Lauro (Stazione Zoologica 'Anton Dohrn', Naples, Italy), and the rabbit polyclonal antibody raised against the mature SP-B peptide isolated from bovine lung (R28031) was generated in the laboratory of Dr J. A. Whitsett. The TTF-1 antibody was used at a dilution of 1:1000 and the mature SP-B antibody at 1:2000. Specificity of 
the TTF-1 and SP-B antibodies was previously established for mammals and chickens (Clark et al., 1995; Zeng et al., 1998; Zhou et al., 1996). Both antibodies cross-react with antigens from adult axolotl Ambystoma mexicanum (Miller et al., 2001) and hence we assume that any immunoreactivity in snapping turtle is either TTF-1 or SP-B.

\section{Immunohistochemistry}

Embryos and hatchlings were killed by intraperitoneal injection of lidocaine hydrochloride, $150 \mathrm{mg} \mathrm{kg}^{-1}$ body mass (BM) (ICN Pharmaceuticals, Inc., Costa Mesa, CA, USA). Lungs were excised from turtle embryos after 61 days of incubation, at the time of pipping, i.e. $64.5 \pm 0.4$ days of incubation (mean \pm S.E.M.), and after hatching, $66 \pm 0.5$ days of incubation (mean \pm S.E.M.). Lungs were fixed in neutral buffered $4 \%$ paraformaldehyde for $20 \mathrm{~h}$ at $4{ }^{\circ} \mathrm{C}$. The tissues were dehydrated in a graded series of ethanol and embedded in paraffin. Transverse sections $(5 \mu \mathrm{m}$ thick) of the thoracic cage of mouse embryos from 18.5 days of gestation and sagittal sections $(5 \mu \mathrm{m})$ of turtle lung were placed on poly-L-lysinecoated slides. Antigen retrieval was performed to enhance immunohistochemical staining for TTF-1 by unmasking antigens. Sections were dewaxed and microwaved in $0.01 \mathrm{moll}^{-1}$ citrate buffer $\left(0.01 \mathrm{moll}^{-1}\right.$ citric acid, $0.01 \mathrm{moll}^{-1}$ sodium citrate, $\mathrm{pH} 6.0$ ) for $7.5 \mathrm{~min}$ on a high power setting to boil, then microwaved at $60 \%$ power for a further $15 \mathrm{~min}$ to simmer using a conventional $900 \mathrm{~W}$ microwave oven (Gown et al., 1991).

All sections, including those for SP-B staining, were placed in $0.5 \%$ hydrogen peroxide for $15 \mathrm{~min}$ to remove endogenous peroxidase activity, blocked with $2 \%$ normal goat serum at room temperature for $2 \mathrm{~h}$, then incubated overnight at $4{ }^{\circ} \mathrm{C}$ with primary antibody and developed using a Vector Elite $\mathrm{ABC}$ kit (Vector Laboratories, Burlingame, CA, USA). Following incubation with secondary antibodies, localization of antigens was developed using nickel-diaminobenzidine, followed by incubation with Tris-cobalt and counterstaining with Nuclear Fast Red. The absence of immunostaining in slides incubated without the primary antibody was used as a negative control, and the fetal mouse lung was used as a positive control for every immunostaining. Slides were viewed and photographed on Kodak 64T tungsten film. Visualisation and interpretation was carried out as previously described (Zeng et al., 1998; Zhou et al., 1996).

\section{Lavage protocol}

Eggs were sampled after 56 and 61 days of incubation, the time of pipping, and following hatching. Embryos and hatchlings were killed by intraperitoneal injection of lidocaine hydrochloride (150 $\mathrm{mg} \mathrm{kg}^{-1} B M$; ICN Pharmaceuticals, Inc., Costa Mesa, CA, USA). Turtles were cannulated via the trachea with a 26-gauge syringe and the lungs were lavaged with three volumes of chilled isotonic saline $\left(0.15 \mathrm{moll}^{-1}\right.$ $\mathrm{NaCl}$ ), which was injected into, and withdrawn from, the lungs three times per volume. Volumes $(0.2-0.5 \mathrm{ml})$ of a $0.5-\mathrm{ml}$ reservoir were injected into the lungs as embryos increased in mass, resulting in an increased lavage volume of 0.05-0.13 $\mathrm{ml} \mathrm{g}^{-1}$ BM. The lavage was centrifuged (Beckman model TJ-6 centrifuge) at $150 \mathrm{~g}$ for $5 \mathrm{~min}$ at $4{ }^{\circ} \mathrm{C}$ to remove cellular debris. The supernatant was snap-frozen in liquid nitrogen and freeze-dried. Lyophilized lavage was stored at $-80^{\circ} \mathrm{C}$ prior to further analyses. Lavaged lungs were blotted dry on paper towel, snap-frozen, freeze-dried and weighed on a Mettler precision balance.

\section{Lipid analyses}

Lyophilized lavage was reconstituted in $2 \mathrm{ml}$ of deionized (Millipore) water and lipids were extracted using chloroform:methanol (1:2 v/v) (Bligh and Dyer, 1959). The concentration of lipids in the lavage from embryos at day 56 of incubation was extremely low. So the lavage from two siblings was pooled. Individual lavage samples were maintained for all other sampling times. Each sampling point contained equivalent numbers of embryos from each clutch. All chemicals used were of analytical grade or higher. Total phosphorus $\left(\mu \mathrm{g} \mathrm{mg}^{-1}\right.$ dry lung) was quantified (Bartlett, 1959) and total phospholipid was calculated by multiplying the total phosphorus by a factor of 25 , as total phospholipid comprises $4 \%$ phosphorus (Daniels et al., 1989). Disaturated phospholipids and neutral lipids were separated on activated aluminum oxide columns by adsorption chromatography (Mason et al., 1976). This method may overestimate the disaturated phospholipid fraction in highly unsaturated samples by detecting a minute quantity of monoenoic species (Veldhuizen et al., 1998); however, it is satisfactory when used to compare values between sampling points. Disaturated phospholipid content ( $\mu \mathrm{g} \mathrm{mg}^{-1}$ dry lung) was measured using the phosphorus assay (Bartlett, 1959). The neutral lipids were dried under nitrogen and dissolved in isopropanol at $2{ }^{\circ} \mathrm{C}$. Cholesterol was quantified using a highpressure liquid chromatography system (Daniels et al., 1999) comprising a Waters pumping system (model M-45, Waters, Milford, MA, USA) and an LKB 2157 autosampler (Pharmacia LKB Biotechnology, Uppsala, Sweden). Sample or standard $(20 \mu \mathrm{l})$ was injected onto a Waters ${ }^{18} \mathrm{C}$ Novopak guard and analytical column $(150 \mathrm{~mm} \times 4.6 \mathrm{~mm}$ i.d. $)$ packed with silica spheres $(4 \mu \mathrm{m}$ diameter). Isocratic elution of cholesterol was completed within $32 \mathrm{~min}$ at room temperature using a mobile phase consisting of acetonitrile, isopropanol and water (6:3:1 $\mathrm{v} / \mathrm{v} / \mathrm{v})$. A flow rate of $1 \mathrm{ml} \mathrm{min}^{-1}$ and an operating pressure of $1600 \mathrm{psi}(1 \mathrm{psi}=6.9 \mathrm{kPa})$ were maintained throughout the elution and ultraviolet absorbance was recorded at $210 \mathrm{~nm}$. The detector output was digitised using a Delta Chromatography data system for acquisition of data and integration of peaks (Digital Solutions, Brisbane, QLD, Australia). Standards were assayed in duplicate and were included at the beginning of each run $\left(5-50 \mu \mathrm{g} \mathrm{ml}^{-1}\right)$.

\section{Statistical analyses}

Data are expressed as means \pm S.E.M. Disaturated phospholipid/phospholipid (DSP/PL) is expressed as a percentage, whereas cholesterol/phospholipid (Chol/PL) and cholesterol/disaturated phospholipid (Chol/DSP) are expressed 
as $\mu \mathrm{g} / \mu \mathrm{g}$ ratios. Data were analyzed using a one-way analysis of variance (ANOVA) followed by paired $t$-tests where appropriate after Arcsin transforming the ratios. Statistical significance was set at $P \leq 0.05$.

\section{Results}

\section{Immunohistochemistry}

Positive staining of the TTF-1 antibody occurred in lung tissue of the snapping turtle at all stages sampled (Fig. 1A-C). TTF-1 stained the nuclei of trabecular and respiratory epithelial cells in day-61, pipped and hatchling snapping turtle lung (Figs $1 \mathrm{~A}-\mathrm{C}, 2)$. The degree of immunostaining was lower in animals that had pipped than in day-61 embryos (Figs 1B, 2B), with a further reduction in staining intensity and the number of cells expressing TTF-1 in the hatchling lung (Figs 1C, 2C). The mature bovine SP-B antibody positively stained snapping turtle lung tissue at all sampling points (Fig. 3A-C). In all cases, immunostaining was confined to the cytoplasm of subsets of cells within the gas exchange area (Figs 3A-C, 4), coinciding with the same cell types, that expressed TTF-1. Staining appeared to intensify after hatching (Figs 3C, 4C).
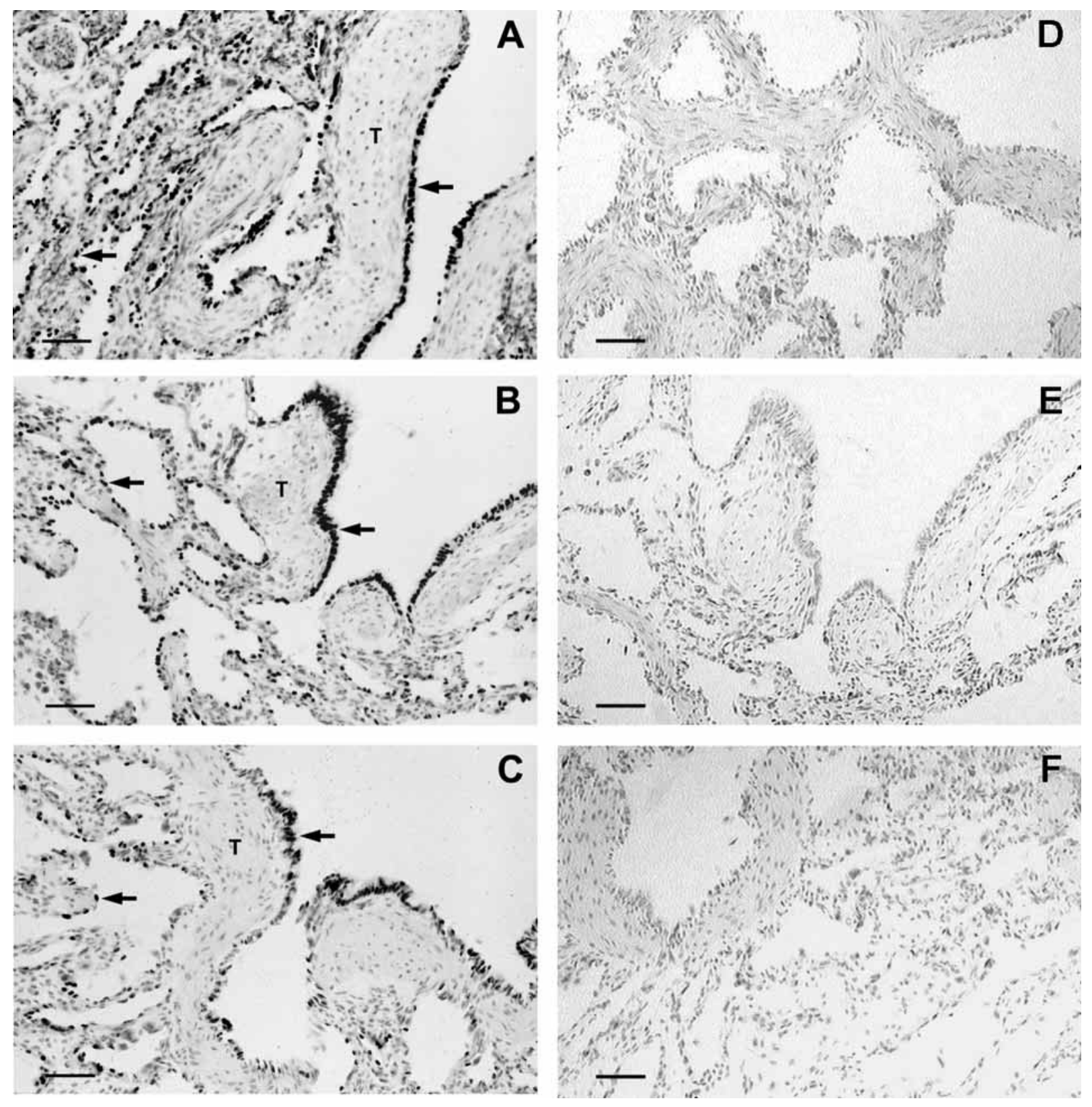

Fig. 1. Immunohistochemical staining of TTF-1 in the developing lung of the snapping turtle. (A-C) TTF-1 was detected in the nuclei of epithelial cells of the trabeculae (T) and gas-exchange area (arrows). The greatest degree of staining occurring at day 61 of incubation (A), and was seen in fewer cells after pipping (B), with the lowest number and intensity after hatching (C). (D-F) Tissues were incubated without primary antibody. Immunostaining was not observed at day 61 (D), after pipping (E) or after hatching (F). Scale bars, $50 \mu \mathrm{m}$. 

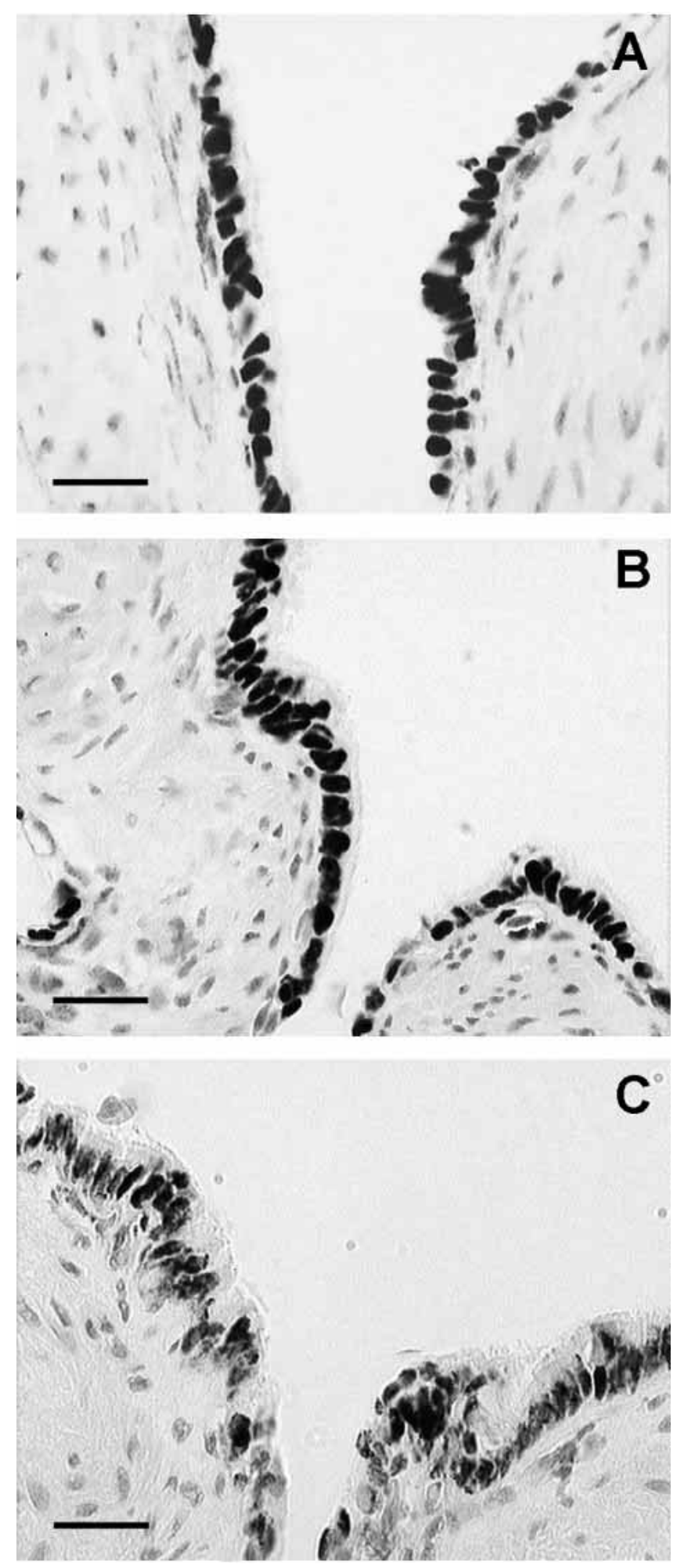

Fig. 2. High-power photomicrograph demonstrating immunohistochemical staining of TTF-1 in the developing lung of the snapping turtle. TTF-1 staining was confined to nuclei of cells within the gas-exchange region and trabecular epithelium in snapping turtles at day 61 of incubation (A), after pipping (B) and after hatching $(\mathrm{C})$. Regions depicted here correspond to areas demarked by the arrows in the corresponding panels of Fig. 1. Scale bars, $20 \mu \mathrm{m}$.

\section{Lipid composition of pulmonary surfactant}

There was no difference in dry lung weight $(D L W)$ and body mass on day $56(D L W, P=0.062 ; B M, P=0.71)$ or on day 61 $(D L W, P=0.12 ; B M, P=0.23$ ) between embryos incubated in the different temperature cabinets. Similarly, there were no differences between the time of pipping $(P=0.69)$ and the time of hatching $(P=0.49)$ across temperature cabinets. Therefore, any effects of cabinet temperature were ignored and data were combined.

Body masses increased significantly from $6.01 \pm 0.18 \mathrm{~g}$ $(N=18)$ in embryos incubated for 56 days to $7.20 \pm 0.14 \mathrm{~g}$ $(N=17)$ in embryos incubated for 61 days $\left(P<10^{-6}\right)$, with an additional increase to $7.92 \pm 0.19 \mathrm{~g}(N=18)$ in embryos that had pipped $(P<0.01)$ and to $8.30 \pm 0.11 \mathrm{~g}(N=16)$ in hatchlings $(P<0.05)$. $D L W$ did not differ among sampling groups $(P=0.11$; day $56,5.64 \pm 0.17 \mathrm{mg}$; day $61,5.57 \pm 0.16$; pip, $5.21 \pm 0.15$; hatch, 5.75 \pm 0.16 ). Total phospholipids, expressed as $\mu \mathrm{g} \mathrm{mg}^{-1}$ dry lung, did not differ between day 56 and day 61, yet significantly increased by approximately 3 -fold after pipping $\left(P<10^{-8}\right)$ and then decreased marginally following hatching $(P<0.05)$ (Fig. 5A). Coincident with the onset of air breathing, disaturated phospholipid content increased approximately 3.5fold from day 61 to pipping $\left(P<10^{-4}\right)$ and did not change thereafter $(P=0.22) \quad$ (Fig. 5B), whereas cholesterol levels increased approximately 2.5 -fold between embryos incubated for 56 days and 61 days $(P<0.05)$, prior to the initiation of pulmonary ventilation, and remained constant following pipping and hatching (Fig. 5C).

The percentage of disaturated phospholipids relative to total phospholipids was comparable between pre-pipped animals (day 56 versus day 61, $P=0.42$ ) (Fig. 6A). However, following pipping, the DSP/PL ratio increased by approximately 1.5 -fold $(P<0.05)$ from day 61 of incubation and did not differ after hatching $(P=0.46)$ (Fig. 6A). Both Chol/PL and Chol/DSP were elevated prior to pipping, then significantly declined after the initiation of air breathing $(P<0.001$ for both tests), remaining unchanged in hatchlings $(P=0.32)$ (Fig. 6B,C).

\section{Discussion \\ Immunohistochemistry}

Mammalian-derived antibodies for TTF-1 and SP-B crossreacted with antigens from snapping turtle lung tissue. Similarly, the same antibodies cross-react with antigens from subsets of cells within distal respiratory epithelium of adult axolotls Ambystoma mexicanum (Miller et al., 2001) and chicken (Zeng et al., 1998). Hence, immunoreactive antigens from snapping turtles are believed to represent the mature surfactant protein SP-B and the transcription factor TTF-1. Consequently, these results suggest a high degree of conservation of both proteins between mammals and turtles, and between mammals and amphibians (Miller et al., 2001). Moreover, the structure of the gene encoding TTF-1 and its polypeptide, and their function, have been conserved between mammals (Ikeda et al., 1995). Since turtles are amongst the most ancient of the amniotes, conservation of TTF-1 and SP- 

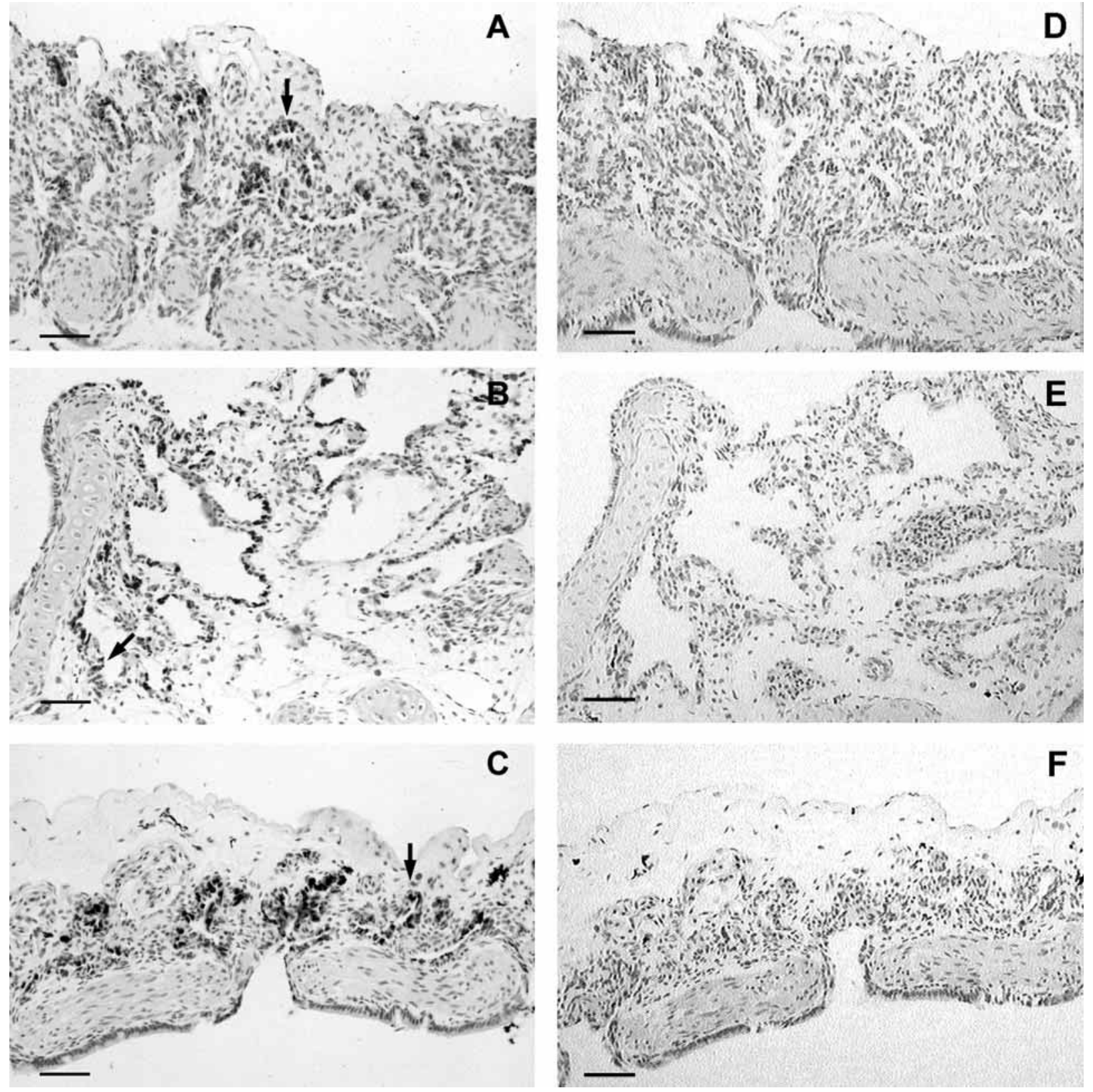

Fig. 3. Immunohistochemical staining of mature SP-B in the developing lung of the snapping turtle. (A-C) SP-B was detected in the cytoplasm of subsets of epithelial cells in the gas-exchange area (arrows) at day 61 of incubation (A), after pipping (B) and after hatching, when staining intensified (C). (D-F) Tissues were incubated without primary antibody. Immunostaining was not observed at day 61 (D), after pipping (E) or after hatching (F). T, trabeculae. Scale bars, $50 \mu \mathrm{m}$.

B between testudian and mammalian lung supports the recent hypothesis of a single origin for vertebrate surfactant (Daniels et al., 1995b, 1998; Sullivan et al., 1998).

TTF-1 is expressed within the nuclei of epithelial cells of the developing airways following 11 weeks and 10 days of gestation in the fetal human and rat lung, respectively (Ikeda et al., 1995; Lazzaro et al., 1991; Stahlman et al., 1996). In these cases immunostaining is restricted to the type II cells and subsets of bronchiolar epithelial cells after birth (Ikeda et al., 1995; Stahlman et al., 1996). Similarly, TTF-1 stained epithelial cell nuclei in both the conducting airways and the gas-exchange area of the developing and hatchling snapping turtle lung. The spatial patterns of both TTF-1 and SP-B expression match those exhibited in the developing mammalian and avian lung. TTF-1 expression precedes and overlaps that of the surfactant proteins, SP-A, SP-B and SP-C in mammals (Stahlman et al., 1996; Zhou et al., 1996) and SPA and SP-B in birds (Zeng et al., 1998). Likewise, both TTF1 and SP-B staining occurred within the same cell types in the developing lung of the snapping turtle. The prevalence of TTF1 staining was lower in the hatchling snapping turtle lung compared to pipping and pre-pipped animals (Fig. 1A-C). 

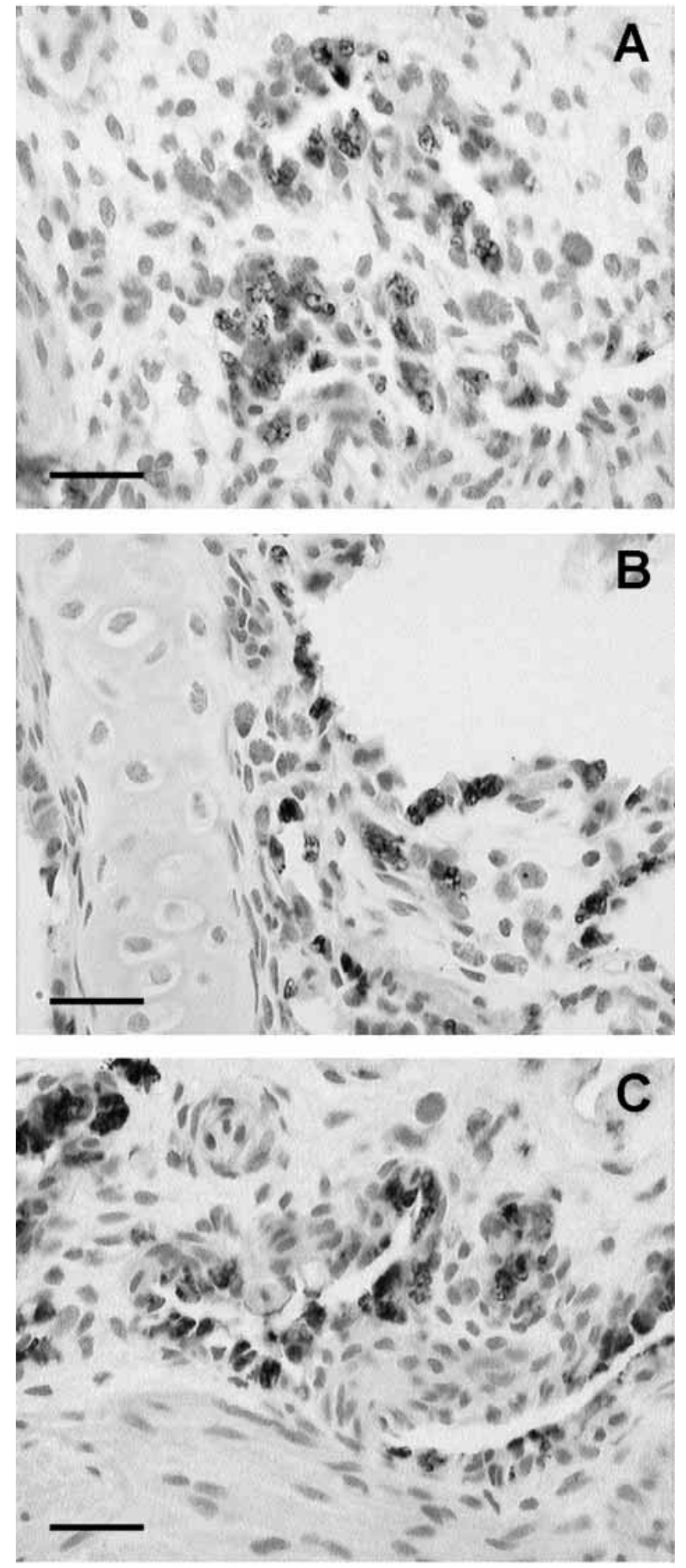

Fig. 4. High-power photomicrograph demonstrating immunohistochemical staining of SP-B in the developing lung of the snapping turtle. SP-B staining was detected in the cytoplasm of subsets of epithelial cells within the gas-exchange region of snapping turtles at day 61 of incubation (A), after pipping (B) and after hatching $(\mathrm{C})$. Regions depicted here correspond to areas demarked by the arrows in the corresponding panels of Fig. 3. Scale bars, $20 \mu \mathrm{m}$.
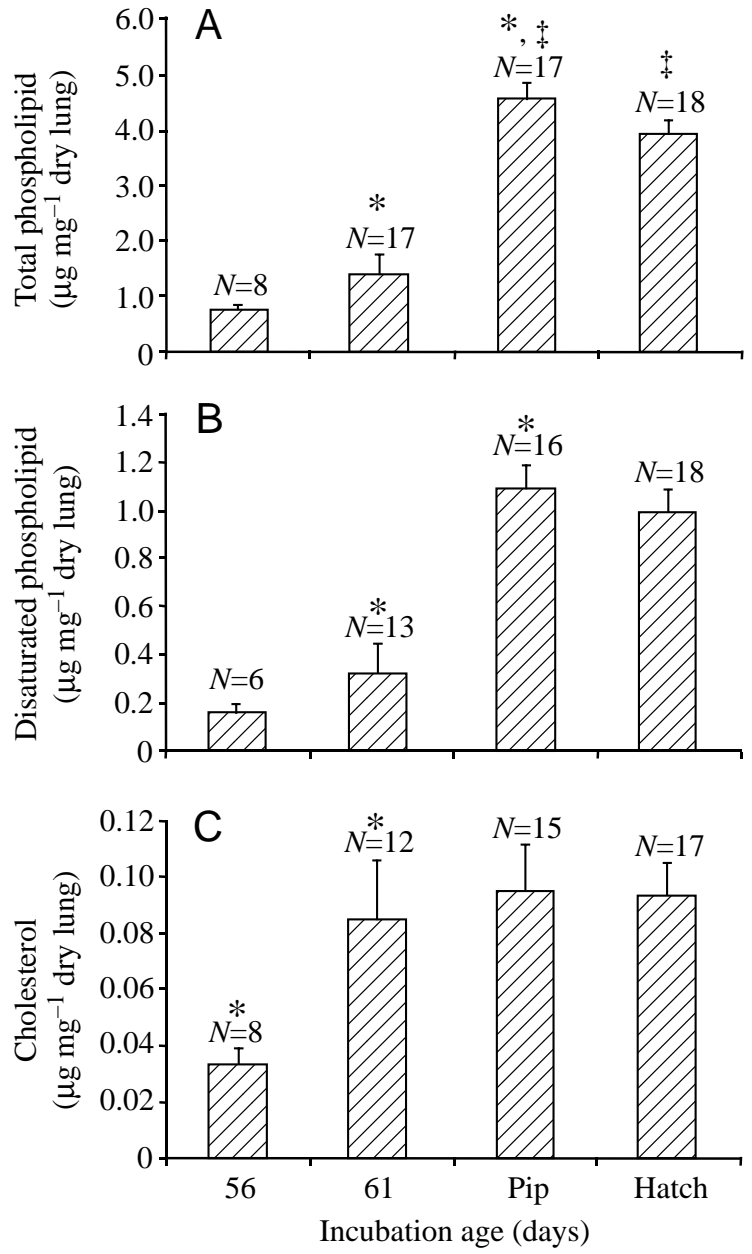

Fig. 5. The absolute amounts of total (A) and disaturated (B) phospholipids and cholesterol (C) in pulmonary surfactant from the developing lung of the snapping turtle. Values are per mg of dry lung (means \pm S.E.M.). Paired symbols indicate a significant difference between adjacent groups. (A) $* P=7.6 \times 10^{-8}, \quad \sharp P=0.05$; $* P=1.5 \times 10^{-5} ;(\mathrm{C}) * P=0.033$.

Similarly, immunostaining of TTF-1 declines in the hatchling chick and postnatal mouse and human lung (Ikeda et al., 1995; Stahlman et al., 1996; Zeng et al., 1998; Zhou et al., 1996). As sampling did not encompass the entire developmental period, it is not known whether TTF-1 staining precedes staining of the surfactant protein, or whether TTF-1 staining occurs at the onset of lung bud formation. Therefore, an upstream role for TTF-1 in lung-specific gene expression (Zhou et al., 1996) cannot be confirmed in the snapping turtle without further investigation. However, the conservation and distribution of TTF-1 and SP-B expression in the turtle lung compared with mammals and birds and the adult axolotl (Miller et al., 2001), support the role of TTF-1 in the regulation of lung development and surfactant homeostasis within the vertebrates.

Ablation of the SP-B gene causes respiratory failure and death immediately after birth in the homozygous mouse, due to disturbances in the cycling of the phospholipids, the 
formation of lamellar bodies and that of tubular myelin (Clark et al., 1995). This demonstrates the necessity of SP-B for lung function after birth. SP-B expression increases in the mouse lung prior to birth (Zhou et al., 1996), as does SP-B mRNA in the developing rat and human lung (Liley et al., 1989; Schellhase et al., 1989) and the mature peptide in newborn rat lavage (Shimizu et al., 1991). Given that increases in surfactant proteins prior to birth reflect the crucial role they play at the onset of pulmonary ventilation in mammals (Zhou et al., 1996), it is likely that this is also true for snapping turtle lung. In turtles, expression of SP-B appeared to intensify after hatching (Figs 3C, 4C) following an elevation in phospholipid and disaturated phospholipid secretion once pulmonary ventilation had commenced (Fig. 5B,C).

\section{Lipid composition of pulmonary surfactant \\ Phospholipids}

In mammals, the principal stimuli for release of pulmonary surfactant after birth include the first deep breaths and input from the sympathetic nervous system. Distortion of the type II cell (Wirtz and Dobbs, 1990), mediated by the dramatic increase in tidal volume (Nicholas and Barr, 1981) and the simultaneous elevation in alveolar partial pressure $\mathrm{PAO}_{2}$, may act synergistically to cause the release of surfactant. Similarly, the lung of the snapping turtle showed increases in both total phospholipids and disaturated phospholipids with the onset of pulmonary ventilation, suggesting that the stimulation for release at pipping is similar to that of birth in mammals. In contrast to eutherian mammals, ventilation does not stimulate surfactant secretion from the isolated perfused lung of the adult bearded dragon (Wood et al., 1995), whereas sympathetic agonists trigger release of phospholipids from both the isolated perfused lung and isolated type II cells of this species (Wood et al., 1995, 1999). Furthermore, the adrenergic agonist isoproterenol maximally stimulates isolated type II cells of chicken embryos to secrete surfactant phospholipids, just prior to pipping (Sullivan and Orgeig, 2001). Thus, it is likely that input from the sympathetic nervous system provides the primary stimulus for secretion at pipping in oviparous vertebrates.

In the snapping turtle lung, the DSP/PL ratio increased after pulmonary ventilation was established (Fig. 6A). Thus there is greater secretion of disaturated phospholipids relative to total phospholipids after pipping, presumably to aid in the elimination of lung fluid and initiation of gas exchange. Furthermore, the subsequent depression in total phospholipids after hatching suggests that there is maximal secretion of surfactant during pipping when pulmonary ventilation is first established. Similarly, the content of total and disaturated phospholipid are maximal in lavage from the green sea turtle Chelonia mydas at the time of pipping (Johnston et al., 2001). Increases in total phospholipids and disaturated phospholipids may be attributable to the elevated activity of the embryo as it struggles to break the eggshell. Indeed, resting metabolic rate and circulating thyroid hormones are elevated between pipping and hatching in the turkey (Christensen et al., 1982) and
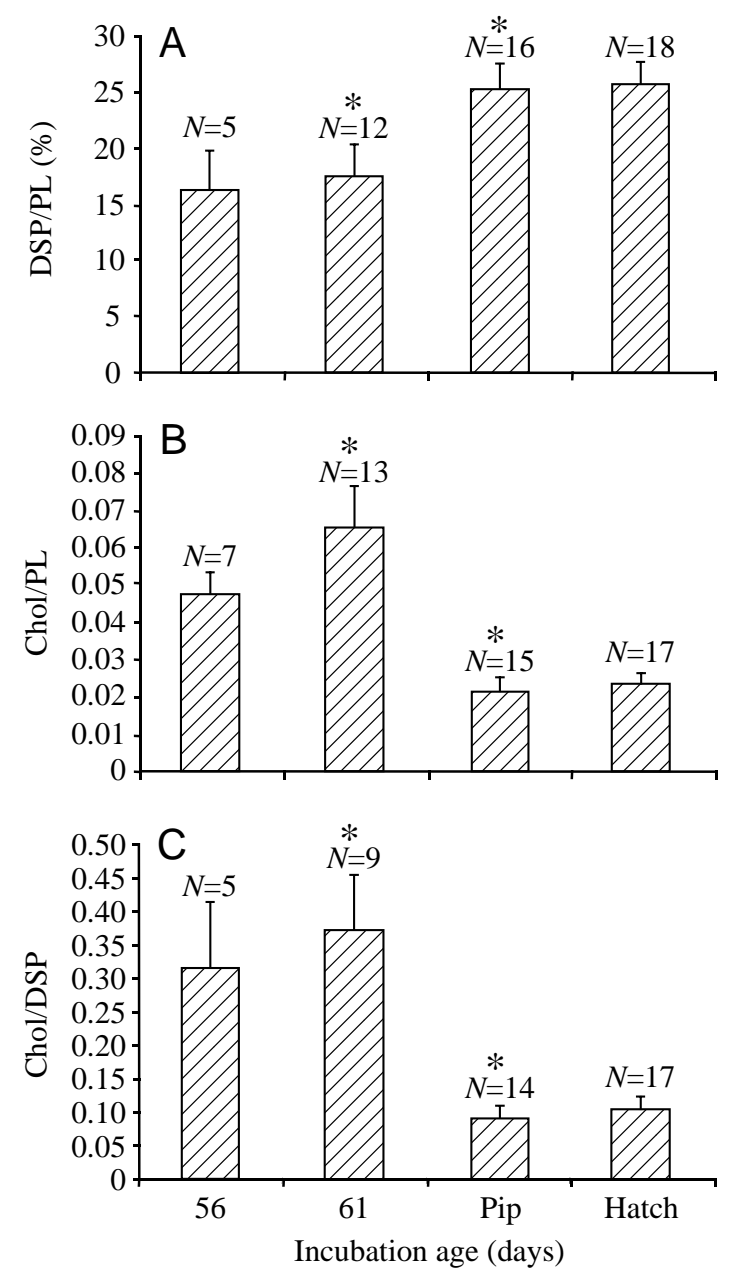

Fig. 6. The relationship between phospholipids and cholesterol in pulmonary surfactant from the developing lung of the snapping turtle, demonstrating (A) disaturated phospholipids (DSP) expressed as a percentage of total phospholipids (PL), (B) the cholesterol $(\mathrm{Chol}) / \mathrm{PL}$ ratio and $(\mathrm{C})$ the Chol/DSP ratio. Values are means \pm S.E.M. Paired symbols indicate a significant difference between adjacent groups. (A) $* P=0.019,(\mathrm{~B}) * P=2.6 \times 10^{-4},(\mathrm{C}) * P=3.2 \times 10^{-4}$.

oxygen consumption increases before pipping in the green sea turtle, C. mydas (Ackerman, 1980). Furthermore, the basal secretory rate of surfactant phospholipids from isolated type II cells of embryonic green sea turtles increased twofold between day 73 of incubation (pre-pip) and hatching (Sullivan et al., 2001). Hence, it appears that the surfactant system matures upon pipping in turtles.

\section{Cholesterol}

Contrary to the amount of phospholipids, the content of cholesterol increased significantly in the snapping turtle lung prior to the initiation of air breathing and remained unchanged thereafter (Fig. 5C). In the developing chicken and lizard lung, the amount of cholesterol does not vary throughout the latter part of incubation, despite increases in the amount and saturation of the phospholipids (Johnston et al., 2000). Likewise, cholesterol remains constant during metamorphosis 
in the tiger salamander, Ambystoma tigrinum, while saturation of the phospholipids declines (Orgeig et al., 1994). In addition, the content of cholesterol increases in tandem with the phospholipids throughout incubation in the sea turtle $C$. mydas (Johnston et al., 2001). It therefore appears that neither the sympathetic surge observed at birth in mammals, nor ventilation, nor increases in $P_{\mathrm{O}_{2}}$ affect cholesterol secretion in the developing snapping turtle lung. Indeed, adrenaline and acetylcholine do not stimulate cholesterol secretion in either the isolated perfused lung (Wood et al., 1995) or isolated type II cells of the adult bearded dragon (Wood et al., 1999). Clearly, factors regulating cholesterol synthesis and/or secretion are independent from those controlling the phospholipids, both within and between species (Johnston et al., 2000, 2001).

Juvenile loggerhead sea turtles Caretta caretta and flatback sea turtles Natator depressus demonstrate much higher Chol/PL and Chol/DSP ratios than reptiles with unicameral lungs (Daniels et al., 1996). Daniels and others suggested that an elevated Chol/DSP ratio may facilitate spreading and respreading of the surfactant following faveolar compression. The Chol/PL and Chol/DSP ratios for hatchling snapping turtles were approximately three times lower than values obtained for juvenile C. caretta (Chol/PL, 0.099 \pm 0.019 ; Chol/DSP, 0.360 \pm 0.047 ) and $N$. depressus (Chol/PL, 0.061 \pm 0.016 ; Chol/DSP, 0.223 \pm 0.057 ) (Daniels et al., 1996) (Fig. 5B,C), yet were similar to those observed in pipped and newly hatched green sea turtles (Johnston et al., 2001). Composition of surfactant differs with diet (Viscardi, 1995) and temperature (Daniels et al., 1996). It is likely, therefore, that differences between juveniles and hatchlings are a result of temperature differentials and utilization of yolk.

The amount of phospholipids and cholesterol recovered from marine turtles Caretta caretta and Natator depressus (Daniels et al., 1996) is an order of magnitude greater than the amounts recovered from the freshwater turtles Malaclemys geographica (Lau and Keough, 1981) and Emydura krefftii (Daniels et al., 1996). Moreover, the content of cholesterol in lavage from hatchling green sea turtles (Johnston et al., 2001) also surpassed that of hatchling snapping turtles. It appears that, whereas the lipid profiles of turtles may be the same, the absolute amounts differ between freshwater and marine species. Such differences may be a result of temperature, which profoundly affects the behaviour of surfactant lipids. Freshwater turtles like the snapping turtle are subjected to a wider range of ambient temperature throughout their life cycle, while sea turtles are exposed to a relatively constant thermal environment. Consequently, the surfactant system of snapping turtles may exhibit a greater degree of plasticity than that of their marine relatives. In addition, snapping turtles have a less complex primary lung structure than sea turtles (Duncker, 1978; Perry, 1989) and a considerably reduced plastron, permitting sagging of the visceral structures upon land. This in turn exerts tension on the dorsally located lungs, causing them to inflate. Thus, on land, inspiration in the snapping turtle is largely passive, while expiration is an active process. When in water, the reverse occurs (Gaunt and Gans, 1969). It is possible that differences in the mechanics of breathing on land may result in differences in the composition of the surfactant between these and other turtles.

\section{Conclusions}

TTF-1 was detected in nuclei of epithelial cells within the gas-exchange area and conducting airways through the latter stages of development in the snapping turtle lung, and expression declined in the hatchling lung. SP-B was detected in the cytoplasm of subsets of cells within the respiratory epithelium both prior to, and subsequent to, the onset of pulmonary ventilation. Therefore, this surfactant protein and its regulating factor appear to be highly conserved among the vertebrates. Given that both proteins exhibited similar patterns of temporal-spatial staining to those observed in the developing mammalian and avian lung, it is suggested that TTF-1 is involved in lung morphogenesis and surfactant protein gene expression in vertebrates. Snapping turtles, like mammals, dramatically increase the amount of saturated and total phospholipids at the onset of pulmonary ventilation, presumably to overcome resistance to inflation and aid lung clearance. Cholesterol increases prior to pulmonary ventilation, demonstrating that synthesis and/or secretion of cholesterol in the developing turtle lung is independently regulated from the phospholipids. Hence, the pattern of development of the surfactant proteins and lipids is conserved among the vertebrates, with maturation of the system occurring at the time of pipping, in preparation for air breathing.

The authors would like to thank Prof. Gary Packard and Dr Kathy Packard for providing laboratory space and for collection and incubation of the eggs. We thank Dr Susan Wert, Ms Sherri Profitt, Ms Kate Davidson and Mr Jonathan Codd for technical assistance in various aspects of the project. We thank staff at the Children's Hospital Medical Center and University Hospital, Cincinnati Ohio. Protocol was approved by the CSU Animal Care and Use Committee, protocol \#98098A-01. This research was funded by an Australian Research Council (ARC) grant to C.B.D., an ARC Research Fellowship to S.O. and an Australian Postgraduate Award, Research Abroad Scholarship and Australian Federation of University Women Cathy Candler Bursary to S.D.J. Additional support was obtained from HL56387 and HL38859 (J.A.W).

\section{References}

Ackerman, R. A. (1980). Physiological and ecological aspects of gas exchange by sea turtle eggs. Amer. Zool. 20, 575-583.

Bartlett, G. R. (1959). Phosphorus assay in column chromatography. J. Biol. Chem. 234, 466-468.

Benson, B. J., Kitterman, J. A., Clements, J. A., Mescher, E. J. and Tooley, W. H. (1983). Changes in phospholipid composition of lung surfactant during development in the fetal lamb. Biochim. Biophys. Acta 753, 83-88.

Bligh, E. G. and Dyer, W. J. (1959). A rapid method of total lipid extraction and purification. Can. J. Biochem. 37, 911-917.

Bohinski, R. J., Di Lauro, R. and Whitsett, J. A. (1994). The lung-specific 
surfactant protein B gene promotor is a target for thyroid transcription factor 1 and hepatocyte nuclear factor 3 , indicating common factors for organ specific gene expression along the foregut axis. Mol. Cell. Biol. 14, $5671-5681$

Bruno, M. D., Bohinski, R. J., Huelsman, K. M., Whitsett, J. A. and Korfhagen, T. R. (1995). Lung cell-specific expression of the murine surfactant protein A (SP-A) gene is mediated by interactions between the SP-A promoter and thyroid transcription factor-1. J. Biol. Chem. 270, 6531-6536.

Christensen, V. L., Biellier, H. and Forward, J. F. (1982). Physiology of turkey embryos during pipping and hatching: 3 . Thyroid function. Poultry Sci. 61, 367-374.

Clark, J. C., Wert, S. E., Bachurski, C. J., Stahlman, M. T., Stripp, B. R., Weaver, T. E. and Whitsett, J. A. (1995). Targeted disruption of the surfactant protein B gene disrupts surfactant homeostasis, causing respiratory failure in newborn mice. Proc. Natl. Acad. Sci. USA 92, 7794-7798.

Daniels, C. B., Barr, H. A. and Nicholas, T. E. (1989). A comparison of the surfactant associated lipids derived from reptilian and mammalian lungs. Respir. Physiol. 75, 335-348.

Daniels, C. B., Orgeig, S. and Smits, A. W. (1995a). The composition and function of reptilian pulmonary surfactant. Respir. Physiol. 102, 121-135.

Daniels, C. B., Orgeig, S. and Smits, A. W. (1995b). Invited Perspective: The evolution of the vertebrate pulmonary surfactant system. Physiol. Zool. 68, 539-566.

Daniels, C. B., Orgeig, S., Smits, A. W. and Miller, J. D. (1996). The influence of temperature, phylogeny, and lung structure on the lipid composition of reptilian pulmonary surfactant. Exp. Lung Res. 22, 267-281

Daniels, C. B., Orgeig, S., Wood, P. G., Sullivan, L. C., Lopatko, O. V. and Smits, A. W. (1998). The changing state of surfactant lipids: New insights from ancient animals. Amer. Zool. 38, 305-320.

Daniels, C. B., Wood, P. G., Lopatko, O. V., Codd, J. R., Johnston, S. D. and Orgeig, S. (1999). Surfactant in the gas mantle of the snail Helix aspersa. Physiol. Biochem. Zool. 72, 691-698.

Duncker, H. R. (1978). General morphological principles of amniotic lungs. In Respiratory Function in Birds, Adult and Embryonic (ed. J. Piiper), pp. 2-15. Berlin: Springer-Verlag.

Fleetwood, J. N. and Munnell, J. F. (1996). Morphology of the airways and lung parenchyma in hatchlings of the loggerhead sea turtle, Caretta caretta. J. Morphol. 227, 289-304.

Gaunt, A. S. and Gans, C. (1969). Mechanics of respiration in the snapping turtle Chelydra serpentina (Linneaus). J. Morphol. 128, 195-228.

Gown, A. M., De Wever, N. and Battifora, H. (1991). Microwave-based antigenic unmasking: a revolutionary new technique for routine immunohistochemistry. Appl. Immunohistochem. 14, 256-266.

Ikeda, K., Clark, J. C., Shaw White, J. R., Stahlman, M. T., Boutell, C. J. and Whitsett, J. A. (1995). Gene structure and expression of human thyroid transcription factor-1 in respiratory epithelial cells. J. Biol. Chem. 270, $8108-8114$.

Janzen, F. J., Wilson, M. E., Tucker, J. K. and Ford, S. P. (1998), Endogenous yolk steroid hormones in turtles with different sex-determining mechanisms. Gen. Comp. Endocrinol. 111, 306-317.

Johnston, S. D., Daniels, C. B. and Booth, D. T. (2001). Development of the pulmonary surfactant system in the green sea turtle, Chelonia mydas. Respir. Physiol. 126, 75-84.

Johnston, S. D., Orgeig, S., Lopatko, O. V. and Daniels, C. B. (2000). Development of the pulmonary surfactant system in two oviparous vertebrates. Am. J. Physiol. 278, R486-R493.

Katz, D. V., Albini, B. and Kite Jr., J. H. (1986). Materno-embryonally transferred antibodies precipitate autoimmune thyroiditis in obese strain (OS) chickens. J. Immunol. 137, 542-545.

Kelly, S. E., Bachurski, C. J., Burhans, M. S. and Glasser, S. W. (1996). Transcription of the lung-specific surfactant protein $\mathrm{C}$ gene is mediated by thyroid transcription factor 1. J. Biol. Chem. 271, 6881-6888.

Khoor, A., Stahlman, M. T., Gray, M. E. and Whitsett, J. A. (1994). Temporal-spatial distribution of SP-B and SP-C proteins and mRNAs in developing respiratory epithelium of human lung. J. Histochem. Cytochem. 42, 1187-1199.

Lau, M. J. and Keough, K. M. W. (1981). Lipid composition of lung and lung lavage fluid from map turtles (Malaclemys geographica) maintained at different environmental temperatures. Can. J. Biochem. 59, 208-219.

Lazzaro, D., Price, M., de Felice, M. and Di Lauro, R. (1991). The transcription factor TTF-1 is expressed at the onset of thyroid and lung morphogenesis and in restricted regions of the foetal brain. Development 113, 1093-1104.

Liley, H. G., White, R. T., Warr, R. G., Benson, B. J., Hawgood, S. and Ballard, P. L. (1989). Regulation of messenger RNAs for the hydrophobic surfactant proteins in human lung. J. Clin. Invest. 83, 1191-1197.

Mason, R. J., Nellenbogen, J. and Clements, J. A. (1976). Isolation of disaturated phosphatidylcholine with osmium tetroxide. J. Lipid Res. 17, 281-284.

Meban, C. (1977). Ultrastructure of the respiratory epithelium in the lungs of the tortoise, Testudo graeca. Cell Tiss. Res. 181, $267-275$.

Meban, C. (1980). Physical properties of surfactant from the lungs of the tortoise Testudo hermanni. Comp. Biochem. Physiol. 67, 253-257.

Meban, C. (1981). Evaporative resistance of pulmonary surfactant films. Experientia 37, 867-868.

Merrill, J. D. and Ballard, R. A. (1998). Antenatal hormone therapy for fetal lung maturation. Clin. Perinatol. 25, 983-997.

Miller, L. D., Wert, S. E. and Whitsett, J. A. (2001). Surfactant proteins and cell markers in the respiratory epithelium of the amphibian, Ambystoma mexicanum. Comp. Biochem. Physiol. A 129, 141-149.

Minoo, P., Hamdan, H., Bu, D., Warburton, D., Stepanik, P. and Delemos, R. (1995). TTF-1 regulates lung epithelial morphogenesis. Dev. Biol. 172, 694-698.

Nicholas, T. E. and Barr, H. A. (1981). Control of release of surfactant phospholipids in the isolated perfused rat lung. J. Appl. Physiol. 51, 90-98.

Orgeig, S., Daniels, C. B. and Smits, A. W. (1994). The composition and function of the pulmonary surfactant system during metamorphosis in the tiger salamander Ambystoma tigrinum. J. Comp. Physiol. B 164, 337-342.

Orgeig, S., Smits, A. W., Daniels, C. B. and Herman, J. K. (1997). Surfactant regulates pulmonary fluid balance in reptiles. Am. J. Physiol. 273, R2013-R2021.

Packard, G. C., Packard, M. J., Miller, K. and Boardman, T. J. (1987). Influence of moisture, temperature and substrate on snapping turtle eggs and embryos. Ecology 68, 983-993.

Pastor, L. M., Ballesta, J., Castells, M. T., Perez Tomas, R., Marin, J. A. and Madrid, J. F. (1989). A microscopic study of the lung of Testudo graeca (Chelonia). J. Anat. 164, 19-39.

Perry, S. F. (1989). Structure and function of the reptilian respiratory system. In Comparative Pulmonary Physiology. Current Concepts (ed. S. C. Wood), pp. 193-236. New York: Marcel Dekker Inc.

Perry, S. F., Darian-Smith, C., Alston, J., Limpus, C. J. and Maloney, J. E. (1989). Histological structure of the lungs of the loggerhead turtle, Caretta caretta, before and after hatching. Copeia 1989, 1000-1010.

Possmayer, F. (1997). Physicochemical aspects of pulmonary surfactant. In Fetal and Neonatal Physiology (ed. R. A. Polin and W. W. Fox), pp. 1259-1275. W. B. Saunders Company.

Prati, M., Calvo, R., Morreale, G. and Morreale de Escobar, G. (1992). Lthyroxine and 3,5,3'-triiodothyronine concentrations in the chicken egg and in the embryo before and after the onset of thyroid function. Endocrinology 130, 2651-2659.

Schellhase, D. E., Emrie, P. A., Fisher, J. H. and Shannon, J. M. (1989). Ontogeny of surfactant apoproteins in the rat. Pediatr. Res. 26, $167-174$.

Schwabl, H. (1993). Yolk is a source of maternal testosterone for developing birds. Proc. Natl. Acad. Sci. USA 90, 11446-11450.

Shimizu, H., Miyamura, K. and Kuroki, Y. (1991). Appearance of surfactant proteins, SP-A and SP-B, in developing rat lung and the effects of in vivo dexamethasone treatment. Biochim. Biophys. Acta 1081, 53-60.

Solomon, S. E. and Purton, M. (1984). The respiratory epithelium of the lung in the green turtle (Chelonia mydas L.). J. Anat. 139, 353-370.

Stahlman, M. T., Gray, M. E. and Whitsett, J. A. (1996). Expression of thyroid transcription factor-1 (TTF-1) in fetal and neonatal human lung. $J$. Histochem. Cytochem. 44, 673-678.

Sullivan, L. C., Daniels, C. B., Phillips, I. D., Orgeig, S. and Whitsett, J. A. (1998). Conservation of surfactant protein A: evidence for a single origin for vertebrate pulmonary surfactant. J. Mol. Evol. 46, 131-138.

Sullivan, L. C. and Orgeig, S. (2001). Dexamethasone and epinephrine stimulate surfactant secretion in type II cells of embryonic chickens. Am. $J$. Physiol. 281, R770-R777.

Sullivan, L. C., Orgeig, S., Wood, P. G. and Daniels, C. B. (2001). The ontogeny of pulmonary surfactant secretion in the embryonic green sea turtle (Chelonia mydas). Physiol. Biochem. Zool. 74, 493-501.

Torday, J. S. and Nielson, H. C. (1981). Surfactant phospholipid ontogeny in fetal rabbit lung lavage and amniotic fluid. Biol. Neonate 39, 266-271.

Veldhuizen, R. A. W., Nag, K., Orgeig, S. and Possmayer, F. (1998). The 
role of lipids in pulmonary surfactant. Biochim. Biophys. Acta 1408, 90-108.

Viscardi, R. M. (1995). Role of fatty acids in lung development. J. Nutr. 125 1645S-1651S.

Weaver, T. E. (1998). Synthesis, processsing and secretion of surfactant proteins B and C. Biochim. Biophys. Acta 1408, 173-179.

Weaver, T. E. and Whitsett, J. A. (1991). Function and regulation of expression of pulmonary surfactant-associated proteins. Biochem. J. 273, 249-264.

Wilson, C. M. and McNabb, F. M. A. (1997). Maternal thyroid hormones in Japanese quail eggs and their influence on embryonic development. Gen. Comp. Endocrinol. 107, 153-165.

Wirtz, H. R. W. and Dobbs, L. G. (1990). Calcium mobilization and exocytosis after one mechanical stretch of lung epithelial cells. Science $\mathbf{2 5 0}$, $1266-1269$.

Wood, P. G., Daniels, C. B. and Orgeig, S. (1995). Functional significance and control of release of pulmonary surfactant in the lizard lung. Am. J. Physiol. 269, R838-R847.

Wood, P. G., Lopatko, O. V., Orgeig, S., Codd, J. R. and Daniels, C. B. (1999). Control of pulmonary surfactant secretion from type II pneumocytes isolated from the lizard, Pogona vitticeps. Am. J. Physiol. 277, R1705-R1711.

Yntema, C. L. (1981). Characteristics of gonads and oviducts in hatchlings and young of Chelydra serpentina resulting from three incubation temperatures. J. Morphol. 167, 297-304.

Zeng, X., Yutzey, K. E. and Whitsett, J. A. (1998). Thyroid transcription factor-1, hepatocyte nuclear factor-3 $\beta$ and surfactant protein A and B in the developing chick lung. J. Anat. 193, 399-408.

Zhou, L., Lim, L., Costa, R. H. and Whitsett, J. A. (1996). Thyroid transcription factor- 1 , hepatocyte nuclear factor- $3 \beta$, surfactant protein $\mathrm{B}, \mathrm{C}$ and clara cell secretory protein in developing mouse lung. J. Histochem. Cytochem. 44, 1183-1193. 